\title{
Informing primary care reform in Greece: patient expectations and experiences (the QUALICOPC study)
}

\author{
Christos Lionis ${ }^{1 *}$, Sophia Papadakis ${ }^{1,2}$, Chrysanthi Tatsi ${ }^{1}$, Antonis Bertsias ${ }^{1}$, George Duijker ${ }^{1}$, \\ Prodromos-Bodosakis Mekouris ${ }^{3}$, Wienke Boerma ${ }^{4}$, Willemijn Schäfer ${ }^{4}$ and on behalf of \\ the Greek QUALICOPC team
}

\begin{abstract}
Background: Primary health care is the cornerstone of a high quality health care system. Greece has been actively attempting to reform health care services in order to improve heath outcomes and reduce health care spending. Patient-centered approaches to health care delivery have been increasingly acknowledged for their value informing quality improvement activities. This paper reports the quality of primary health care services in Greece as perceived by patients and aspects of health care delivery that are valued by patients.

Methods: This study was conducted as part of the Quality and Costs of Primary Care in Europe (QUALICOPC) study. A cross-sectional sample of patients were recruited from general practitioner's offices in Greece and surveyed. Patients rated five features of person-focused primary care: accessibility; continuity and coordination; comprehensiveness; patient activation; and doctor-patient communication. One tenth of the patients ranked the importance of each feature on a scale of one to four, and nine tenths of patients scored their experiences of care received. Comparisons were made between patients with and without chronic disease.

Results: The sample included 220 general practitioners from both public and private sector. A total of 1964 patients that completed the experience questionnaire and 219 patients that completed the patient values questionnaire were analyzed. Patients overall report a positive experiences with the general practice they visited. Several gaps were identified in particular in terms of wait times for appointments, general practitioner access to patient medical history, delivery of preventative services, patient involvement in decision-making. Patients with chronic disease report better experience than respondents without a chronic condition, however these patient groups report the same values in terms of qualities of the primary care system that are important to them.

Conclusions: Data gathered may be used to improve the quality of primary health care services in Greece through an increased focus on patient-centered approaches. Our study has identified several gaps as well as factors within the primary care health system that patient's perceive as most important which can be used to prioritize quality improvement activities, especially within the austerity period. Study findings may also have application to other countries with similar context and infrastructure.
\end{abstract}

Keywords: Primary care, Quality, Patient-centered care, Greece, QUALICOPC, Cross sectional

\footnotetext{
*Correspondence: lionis@galinos.med.uoc.gr

${ }^{1}$ Faculty of Medicine, University of Crete, Heraklion, Crete, Greece

Full list of author information is available at the end of the article
}

(c) The Author(s). 2017 Open Access This article is distributed under the terms of the Creative Commons Attribution 4.0 International License (http://creativecommons.org/licenses/by/4.0/), which permits unrestricted use, distribution, and reproduction in any medium, provided you give appropriate credit to the original author(s) and the source, provide a link to the Creative Commons license, and indicate if changes were made. The Creative Commons Public Domain Dedication waiver (http://creativecommons.org/publicdomain/zero/1.0/) applies to the data made available in this article, unless otherwise stated. 


\section{Background}

Many European countries share the goal of establishing a strong primary health care (PHC) system as part of their health care system [1]. There is good evidence supporting the importance of $\mathrm{PHC}$ in reducing healthcare spending and health disparities [1-3]. Over the past several years, Greece has been actively attempting to improve health care services with a focus on strengthening PHC [4]. The austerity period, which has been in place in Greece for several years, has had a significant impact on the size, structure, quality and effectiveness of health care services [4].

Internationally, patient satisfaction and patient-centered approaches to health care delivery have gained an important place in informing health care reform and quality health care delivery $[5,6]$. Meeting the expectations of the population through patient-centered health care delivery is one of the valued indicators of health system functioning $[1,7]$. Several studies have demonstrated that a positive relationship between general practitioners (GPs) and their patients is associated with reduced health care spending [8] and there is good evidence to show that the relationship between patients and $\mathrm{PHC}$ professionals can be reinforced by improved communication during practice visits [9-11] The key elements of patient-centered approaches are: eliciting patient perspectives, responding to patient concerns, giving information; partnership building; engaging the patient in participatory decision-making; and developing a follow-up health care plan together [12-14].

In Greece, PHC is delivered through a combination of publically funded state health services and by private Family Physicians/GPs. The public service is delivered through Health Centres, which are accessible 24 hours a day, 7 days a week, and located primarily in rural areas. GPs provide their services on a fee-for-service basis in privately owned offices $[4,15]$.

The public PHC services can provide a number of services including diagnostic, curative and preventive health, facilitating multi-disciplinary team of professionals such as GPs, pediatricians, microbiologists, dentists, midwifes, radiologists, and nursing personnel. On the other hand, patients are free to choose whether they will visit a public PHC service or a specialist from the private sector. Greek patients often have unequal access to standard PHC services, depending on factors such as geographical accessibility and ability to pay for a private physician. The PHC system in Greece has reported low performance in several areas of quality-based care [4, 16]. A recently published paper of Schäfer et al. reported on data from the Quality and Costs of Primary Care in Europe (QUALICOPC), which examined quality indicators as perceived by patients in 34 countries including Greece [17]. Five dimensions of person-focused primary care have been assessed by the QUALICOPC project: accessibility, continuity and coordination, comprehensiveness, patient activation, and doctor-patient communication $[1,18]$. The paper clearly highlighted the tail position of the Greek health care system as perceived by patients, in particular in the areas of accessibility, continuity and patient involvement [17]. These results validate the urgency of continued efforts to reform $\mathrm{PHC}$ in Greece and it is considered as a high priority for a country that has been seriously damaged by the austerity period.

Motivated by these alarming observations this paper sought to conduct a more in-depth exploration of the quality of PHC services in Greece as assessed by patients and explores aspects of health care delivery that are valued by patients. Comparisons are also made between patients with and without chronic disease as we hypothesize experiences will differ across these patient sub-groups given the acute care orientation of PHC services in Greece. Finally, we reflect on possible solutions that might inform health care reform activities moving forward. The Clinic of Social and Family Medicine at the University of Crete jointly with the Greek Association of General Practitioners (ELEGEIA) were responsible for the implementation of the QUALICOPC project in Greece. Their main responsibilities included the selection of GP practices, the recruitment of GPs serving in all healthcare centres located in all seven health regions of Greece. Additionally they were responsible for the distribution of the questionnaires and data collection, storage, and analysis.

\section{Methods}

\section{Setting and design}

A cross-sectional survey was conducted of both GPs and a sample of patients from their practice. We aimed to sample one GP from each of the 218 public PHC centers located in the seven health care regions in Greece. A GP-coordinator was identified in each of the health regions to assist with local recruitment activities. The Clinic of Social and Family Medicine, with the assistance of the regional coordinators and ELEGEIA sent invitations to a list of 300 GPs working in the 218 public PHC centres with the aim was to recruit one GP per PHC centre. A total of 203 GPs accepted participation while 15 denied participation, thus 15 (6.9\%) PHC centres were not represented in the sample. If more than one GP expressed interest in participation from the same health centre, the first person to respond was included in the sample. Apart from the sample of GPs serving in the public sector, we invited 25 GPs serving in the private sector. They were contacted alphabetically from an available list of 130 GPs eligible serving in the private sector located in the 5th and 7th health regions of Greece and 17 (68\%) accepted participation. From each GPs practice a sample of 10 consecutive patients from 
their practice was surveyed. Written informed consent was obtained from all patients and participant responses remained anonymous. Ethical approval was received from Bioethical Committee of the University General Hospital of Heraklion (number protocol: 7655/7-7-2011).

\section{Data collection}

Study data collection activities occurred between February 2011 and November 2012. Patient recruitment took place between 8:00 am and 15:00 pm in order to capture a wide range of service users. A trained field worker over saw data collection activities at the clinic. Field workers invited consecutive patients who had a face-to-face consultation with the GP and who were over the age of 18 years, and able to speak and read Greek were surveyed, until a sample of 10 questionnaires per practice was achieved. Data was collected at the end of the consultation with the GP. All participants completed a informed consent. Nine tenths of participants completed the patient experience questionnaire and one tenth completed the patient values questionnaire. Details of the QUALICOPC study protocol have been published elsewhere $[1,17,18]$.

\section{Measures}

The QUALICOPC Patient Experiences and Patient Values Questionnaires were used to collect data. The questionnaires were developed by the QUALICOPC Consortium and are based on PHAMEU framework [1]. Patients rated the five dimensions of person-focused primary care: accessibility, continuity and coordination, comprehensiveness, patient activation, and doctor-patient communication [1, 18]. The Patient Experience Questionnaire asked patients to indicate whether they agreed with the statement by selecting 'yes' or 'no' answers. The Patient Values Questionnaire asked patients to rank the importance of each of the statements contained in the patient experience survey using a 1-4 scale, 1 (not important) to 4 (very important). Socio-demographic data (age, gender, employment status), presence of chronic disease(s) ('Do you have a longstanding disease or condition such as high blood pressure, diabetes, depression, asthma or another longstanding condition?') and overall health status ('How would you describe your health status in general?') were collected from all participants. The English version of the questionnaires were translated into Greek using a forth-and back translation procedure.

\section{Statistical analysis}

Characteristics of participants were summarized using descriptive statistics. Univariate comparisons were performed for patients with and without chronic disease using Pearson's chi-squared test for categorical data. Patient responses for the values survey were recoded so that $1=$ very important and $0=$ all other responses. We choose to focus the analysis on the categorization of values as "very important" due to the ceiling effect that was seen when positive responses (i.e. "important" and "very important") were combined. Missing data was minimal and was not replaced. For each variable missing values are reported in the tables. All analyses were conducted using the Statistical Package for Social Sciences (SPSS) Version 21.

\section{Results}

Two-hundred and twenty GPs within the seven health regions agreed to participate in the study. A total of 2220 patients completed study questionnaires (10 per GP practice); however 37 surveys were not legible and were excluded from the analysis. In total 2183 patients were included in the analysis (1964 patients who completed the Patient Experience Questionnaire and 219 patients completed the Patient Values Questionnaire). The primary reason for ineligibility was the inability to read/ write in Greek.

\section{Demographic characteristics}

Table 1 presents the socio-demographic characteristics of patients sampled. Almost $90 \%$ of participants were living with other adults and had children. Close to one third, reported a household income that was below average. Almost, forty-one percent of respondents to the Patient Experience Questionnaire and 53.7\% of respondents to the Patient Values Questionnaire reported the presence of a chronic disease.

\section{Health status and primary care service use patterns}

Tables 2 and 3 present information on the health status of patients and PHC service use patterns for the overall sample and those with and without a chronic illness. Fifty nine percent of participants described their health status as good or very good. As would be expected individuals who did not have a diagnosed chronic disease reported significantly better health status than individuals with a chronic illness. Among patients sampled, 10.8\% of patients with a chronic disease reported not having a personal physician compared to $31.9 \%$ of patients without a chronic disease. During the past 6 months, one in four participants consulting a GP more than 5 times in the previous 12-months. Among patients with chronic illness, the proportion of patients with 5 or more consults increased to $38 \%(p<0.0001)$. The main reason for PHC consult was for a prescription $(44.9 \%)$ and the majority of patients seen for prescriptions were patients with chronic illness (61.8\%).

\section{Patient experience questionnaire}

Tables 3 and 4 present the results regarding participant's experiences at the GP consultation at which they were 
Table 1 Socio-demographic characteristics of respondents to Patient Experience and Patient Values questionnaires

\begin{tabular}{lll}
\hline Variable & $\begin{array}{l}\text { Responders patient } \\
\text { experience survey } \\
n=1964\end{array}$ & $\begin{array}{l}\text { Responders patient } \\
\text { values survey } \\
n=219\end{array}$ \\
\hline Mean Age, years (SD) & $\begin{array}{l}52.7( \pm 16.5) \\
\mathrm{n}(\%)\end{array}$ & $\begin{array}{l}51.9( \pm 14.5) \\
\mathrm{n}(\%)\end{array}$ \\
Sex $^{\mathrm{a}}$ & & \\
Male & $863(44.1 \%)$ & $93(42.5 \%)$ \\
Female & $1093(55.9 \%)$ & $126(57.5 \%)$ \\
Were born in Greece? & & \\
Yes & $1867(95.4 \%)$ & $215(98.2 \%)$ \\
No & $89(4.6 \%)$ & $4(1.8 \%)$
\end{tabular}

Other adults living in your household ${ }^{c}$

$\begin{array}{lll}\text { Yes } & 1729(88.3 \%) & 195(89.4 \%) \\ \text { No } & 229(11.7 \%) & 23(10.6 \%)\end{array}$

Children in your household? ${ }^{d}$

Yes

No

$1243(63.4 \%)$

$718(36.6 \%)$

Years of formal education ${ }^{\mathrm{e}}$

0-9 years

$721(37.0 \%)$

9-12 years

$654(33.6 \%)$

$>12$ years

$573(29.4 \%)$

Current employment status ${ }^{\mathrm{f}}$

Employed

Student

Unemployment

Retired

$827(42.3 \%)$

$89(4.5 \%)$

$168(8.6 \%)$

$590(30.2 \%)$

Other

$286(14.7 \%)$

Household income $e^{\mathrm{g}}$

Below average

$587(29.9 \%)$

Around average

$1245(63.5 \%)$

Above average

$128(6.5 \%)$

Presence of chronic illness ${ }^{\text {h }}$

Yes

$792(40.6 \%)$

$1158(59.4 \%)$

$S D$ standard deviation

Patient Experience Survey: ${ }^{\mathrm{a}} n=1956 ;{ }^{\mathrm{b}} n=1956 ;{ }^{\mathrm{c}} n=1958 ;{ }^{\mathrm{d}} n=1961$;

${ }^{\mathrm{e}} n=1948 ;{ }^{\mathrm{f}} n=1960 ;{ }^{\mathrm{g}} n=1960 ;{ }^{\mathrm{h}} n=1950$

Patient Values Survey: ${ }^{\mathrm{a}} n=219_{i}{ }^{\mathrm{b}} n=219{ }^{\mathrm{b}} \mathrm{b}=219 ;{ }^{\mathrm{c}} n=218{ }^{\mathrm{d}} n=217$;

${ }^{\mathrm{e}} n=215 ;{ }^{\mathrm{f}} \mathrm{n}=219 ;{ }^{\mathrm{g}} \mathrm{n}=219 ;{ }^{\mathrm{h}} \mathrm{n}=218$

surveyed for each of the 5 main dimensions assessed. We review main findings for each dimension below.

\section{Accessibility}

Most participants live within 20 min of their GPs office. The majority of patients did not book an appointment for their clinic visit with more than $40 \%$ of respondents reported waiting more than $30 \mathrm{~min}$ to see the GP.
Among the $27.3 \%$ of participants who reported that they had to schedule an appointment with their GP and most reported the appointment booking to be easy. Most patients felt the GP spent enough time with them. Twentytwo percent reported they were not able to access GPs office in the evening or weekend.

\section{Continuity \& coordination}

Among patients who reporting having a personal GP, 9.2\% were surveyed at an appointment with a different GP from the same practice/centre and $10.3 \%$ had a personal GP who was located in a practice other than that from which they were surveyed. Approximately half of patients sampled reported that the GP had their medical history available in front of them, although patients with chronic disease were significantly more likely to report the GP had their medical history available. Seventyseven per cent of participants reported that within the last 2 years the GP conducted a medication reconciliation and participants with a chronic disease were significantly more likely to report receiving lifestyle advice and reported having their medication history documented compared to individuals without a chronic disease. Half of participants felt they were able to receive a referral to a medical specialist when appropriate via the GP.

\section{Communication \& patient-centred care}

Almost 95\% of participants felt the GP was polite and 93\% reported that the GP listened carefully during the physical examination.

\section{Comprehensiveness}

Seventy-four percent of participants mentioned that the GP asked them about other problems, beyond that for which they came to clinic to address while $81 \%$ reported that the GP was very helpful also with personal problems and concerns. Eighty-one percent of patients with chronic disease reported receiving advice related to staying healthy (diet, smoking, alcohol), this fell to $60 \%$ among individuals without a chronic disease $(P<0.0001)$.

\section{Patient involvement}

Eighty-six percent of the participants identified that after the visit with the GP that they felt better able to deal with their health problem than before. However, only $74 \%$ of respondents reported that the GP included them in their decisions about treatment.

\section{Patient values questionnaire}

Table 5 presents data regarding the proportion of patients who ranked each item as very important for each domain of the Patient Values Questionnaire. Patients identified knowing in advance which doctor they will see for their consultation, that the physician does not cancel 
Table 2 Participant health status, frequency of GP visit, and reason for current visit overall and by presence of a chronic disease

\begin{tabular}{|c|c|c|c|c|}
\hline Variable & $\begin{array}{l}\text { Total } \\
\text { n (\%) }\end{array}$ & $\begin{array}{l}\text { Patients with } \\
\text { chronic disease } \\
\mathrm{n}(\%)^{\mathrm{a}}\end{array}$ & $\begin{array}{l}\text { Patients without } \\
\text { chronic disease } \\
\mathrm{n}(\%)^{\mathrm{a}}\end{array}$ & $p$-value \\
\hline $\begin{array}{l}\text { How would you describe your health } \\
\text { status in general: }\end{array}$ & & & & $<0.0001$ \\
\hline Very good & $409(20.9 \%)$ & $52(4.5 \%)$ & $353(44.9 \%)$ & \\
\hline Good & $750(38.4 \%)$ & $428(37.1 \%)$ & $317(40.3 \%)$ & \\
\hline Satisfactory & $617(31.4 \%)$ & $502(43.5 \%)$ & $111(14.1 \%)$ & \\
\hline Poor & $178(9.1 \%)$ & $171(14.8 \%)$ & $6(0.8 \%)$ & \\
\hline $\begin{array}{l}\text { Do you have your own personal physician who } \\
\text { you consult when you are ill? }\end{array}$ & & & & $<0.0001$ \\
\hline Yes & 1567 (80.6\%) & 1022 (89.2\%) & $536(68.1 \%)$ & \\
\hline No & $378(19.4 \%)$ & $124(10.8 \%)$ & 251 (31.9\%) & \\
\hline $\begin{array}{l}\text { Over the past six months, how often did you visit } \\
\text { or consulted a general practitioner? }\end{array}$ & & & & $<0.0001$ \\
\hline Never & $446(22.9 \%)$ & 108 (9.6\%) & 337 (46.0\%) & \\
\hline Once & $405(20.8 \%)$ & $181(16.1 \%)$ & $221(30.2 \%)$ & \\
\hline 2-4 times & $545(28.0 \%)$ & 409 (36.4\%) & $129(17.6 \%)$ & \\
\hline$\geq 5$ times & $475(24.4 \%)$ & 427 (38.0\%) & $45(6.1 \%)$ & \\
\hline Do not know & $78(4.0 \%)$ & $27(2.3 \%)$ & $51(6.5 \%)$ & \\
\hline \multicolumn{5}{|l|}{ Reason of current visit ${ }^{\mathrm{e}}$} \\
\hline Sick/Unwell & $729(37.3 \%)$ & 387 (33.6\%) & 338 (42.9\%) & $<0.0001$ \\
\hline Medical check-up & $422(21.6 \%)$ & $262(22.7 \%)$ & $258(20.1 \%)$ & 0.160 \\
\hline Prescription & 877 (44.9\%) & $713(61.8 \%)$ & 157 (19.9\%) & $<0.0001$ \\
\hline Referral & $216(11.0 \%)$ & $140(12.1 \%)$ & $75(9.5 \%)$ & 0.070 \\
\hline Health certificate & $106(5.4 \%)$ & 41 (3.6\%) & $64(8.1 \%)$ & $<0.0001$ \\
\hline Second opinion & $128(6.5 \%)$ & $77(6.7 \%)$ & $50(6.3 \%)$ & 0.771 \\
\hline Other & $130(6.6 \%)$ & 43 (3.7\%) & $86(10.9 \%)$ & $<0.0001$ \\
\hline
\end{tabular}

abed on 1950 cases for the variable presence of chronic disease

${ }^{\mathrm{b}}$ Based on sample size of 1954 ; ${ }^{\mathrm{C}}$ Based on a sample size of $1945 ;{ }^{\mathrm{d}}$ Based on a sample size 1949; ${ }^{\mathrm{e}}$ Based on a sample size of 1955

their appointment, and that the doctor is prepared for the consultation was of significant importance. Participants reported aspects of the GP encounter that were very important to be that the GP listened to them attentively $(68.8 \%)$, is calm $(59.4 \%)$ and treats them as a person and not as medical problem (57.8\%). During the consultation, the following factors were ranked as very important: the physician checks with patient to ensure they have understood everything communicated (67.1\%) and the physician is respectful during the physical examination and does not interrupt them (46.8\%). Patients identified the ability to be honest and to talk in detail with their physician about their health problem as very important. Most patients (64.7\%) felt it was very important to be informed by their physician about what to do if something goes wrong with their treatment. There were no significant differences between respondents without a chronic disease and those with chronic disease in terms of values related to primary care. The only exception was that the doctor asking if they had any questions was identified as very important by a larger proportion of respondents without a chronic disease.

Table 6 summarizes the top 11 values of the primary care interactions that were identified by respondents as well as the corresponding assessment.

\section{Discussion}

\section{Main findings of the study}

Over the past several years, Greece has been attempting to reform national health care services with a focus on strengthening PHC delivery in an effort to meet the needs of the population and ensure the efficient use of public resources [4]. As part of these quality improvement efforts several system-level changes have been by the Greek government including the establishment of the National Organization for Healthcare Provision as a unified central healthcare insurer, the establishment of an electronic prescribing system, and the creation of a Primary Healthcare Network [4, 19]. Progress in terms of achieving this goal has however received significant 
Table 3 Participant assessment of GP accessibility according to presence of chronic disease

\begin{tabular}{|c|c|c|c|c|}
\hline Variable & $\begin{array}{l}\text { Overall } \\
\mathrm{n}(\%)\end{array}$ & $\begin{array}{l}\text { Patients with } \\
\text { chronic disease } \\
\mathrm{n}(\%)\end{array}$ & $\begin{array}{l}\text { Patients without } \\
\text { chronic disease } \\
\mathrm{n}(\%)\end{array}$ & $p$-value \\
\hline $\begin{array}{l}\text { How long does it take to go from your home } \\
\text { to the Primary care unit? }\end{array}$ & & & & 0.028 \\
\hline$<20 \min$ & $1335(68.0 \%)$ & $765(66.2 \%)$ & $559(70.6 \%)$ & \\
\hline $20-40 \mathrm{~min}$ & $433(22.1 \%)$ & $271(23.4 \%)$ & $160(20.2 \%)$ & \\
\hline $40-60 \mathrm{~min}$ & $127(6.5 \%)$ & $87(7.5 \%)$ & $40(5.1 \%)$ & \\
\hline$>1 \mathrm{~h}$ & $56(2.9 \%)$ & $29(2.5 \%)$ & $27(3.4 \%)$ & \\
\hline $\begin{array}{l}\text { Did you have to make an appointment for your } \\
\text { visit to the GP? }\end{array}$ & & & & 0.007 \\
\hline Yes & $523(27.3 \%)$ & $333(29.4 \%)$ & $183(23.8 \%)$ & \\
\hline No & $1392(72.7 \%)$ & $800(70.6 \%)$ & $587(76.2 \%)$ & \\
\hline Was it easy to make an appointment? & & & & 0.117 \\
\hline Yes & $474(86.2 \%)$ & $294(84.2 \%)$ & $172(89.1 \%)$ & \\
\hline No & $76(13.8 \%)$ & $55(15.8 \%)$ & $21(10.9 \%)$ & \\
\hline How many days did you wait for today's visit? & & & & 0.546 \\
\hline None & $171(32.4 \%)$ & $107(31.7 \%)$ & $58(32.2 \%)$ & \\
\hline One day & $143(27.1 \%)$ & $86(25.4 \%)$ & $56(30.6 \%)$ & \\
\hline 2-7 days & $125(23.7 \%)$ & 85 (25.1\%) & 40 (21.9\%) & \\
\hline$>7$ days & 89 (16.9\%) & $60(17.8 \%)$ & $28(15.3 \%)$ & \\
\hline Don't know & 25 (4.5\%) & 11 (3.2\%) & 13 (6.6\%) & \\
\hline $\begin{array}{l}\text { How long did you have to wait to see your } \\
\text { doctor when you arrived today? }\end{array}$ & & & & $<0.0001$ \\
\hline$<15 \min$ & 553 (28.7\%) & 295 (25.7\%) & $258(33.0 \%)$ & \\
\hline $15-30 \mathrm{~min}$ & $598(31.0 \%)$ & $342(29.8 \%)$ & $256(32.7 \%)$ & \\
\hline $30-45 \mathrm{~min}$ & 378 (19.6\%) & $246(21.5 \%)$ & 132 (16.9\%) & \\
\hline $45-60 \mathrm{~min}$ & 184 (9.5\%) & $123(10.7 \%)$ & 61 (7.8\%) & \\
\hline$>1 \mathrm{~h}$ & $203(10.5 \%)$ & 135 (11.8\%) & 68 (8.7\%) & \\
\hline Don't know & 12 (0.6\%) & $5(0.4 \%)$ & 7 (0.8\%) & \\
\hline $\begin{array}{l}\text { It is difficult to see a GP in the evenings, } \\
\text { at night and in the weekend? }\end{array}$ & & & & 0.509 \\
\hline Yes & 421 (21.9\%) & $251(22.0 \%)$ & $170(21.7 \%)$ & \\
\hline No & 1046 (54.4\%) & $642(56.3 \%)$ & 404 (51.6\%) & \\
\hline Don't know & 457 (23.8\%) & 248 (21.7\%) & 209 (26.7\%) & \\
\hline
\end{tabular}

$p$-values report on significance between $t$-test comparison by presence of chronic disease

${ }^{\mathrm{a}}$ Based on 1964 cases unless otherwise indicated; ${ }^{\mathrm{b}}$ Based on 792 cases unless otherwise indicated; ${ }^{\mathrm{c}}$ Based on 1158 cases unless otherwise indicated

criticism $[4,19,20]$. A 2013 report on the state of primary care in Greece reported that Greece lacks key characteristics of strong primary care and should be a priority of health care reform activities moving forward [4].

The QUALICOPC project provided a framework to study patient centeredness at the country level, by exploring to patient's experiences and expectations as it relates to primary care health delivery $[1,17,18]$ and by comparing responses among patient with and without chronic disease to determine if these groups of patients differ in terms of experience and values. Our study found, that overall most patients surveyed reported good rates of satisfaction with their experience in the health care system. This is a promising finding given that our study was conducted during the austerity period in Greece, which has had significant impact on funding for health care services and personnel. However, several areas for improvement were also identified, including issues of accessibility, patient-centeredness, patient involvement and continuity of care, which we discuss here.

Factors which were ranked as very important by the majority of study participants are summarized in Table 7. In terms of accessibility, patients have identified the distance of PHC offices from their home or work, and not 
Table 4 Participant experience assessment by primary care domain overall and according to presence of chronic disease

\begin{tabular}{|c|c|c|c|c|}
\hline Variable & $\begin{array}{l}\text { \% Overall sample } \\
n=1964\end{array}$ & $\begin{array}{l}\text { \% Patients with } \\
\text { chronic disease } \\
n=1158\end{array}$ & $\begin{array}{l}\text { \% Patients w/out } \\
\text { chronic disease } \\
n=792\end{array}$ & $p$-value* \\
\hline \multicolumn{5}{|l|}{ Accessibility } \\
\hline Opening hours are too restricted & 28.8 & 30.8 & 25.7 & 0.025 \\
\hline If I need a home visit I can get one & 71.2 & 73.6 & 67.4 & 0.009 \\
\hline The practice is close to where I live or work & 81.5 & 80.1 & 83.7 & 0.048 \\
\hline I had to wait too long on the phone & 11.4 & 10.7 & 12.6 & 0.248 \\
\hline The doctor did not take sufficient time & 83.4 & 82.5 & 84.8 & 0.190 \\
\hline It was easy to make an appointment & 86.2 & 84.2 & 89.1 & 0.117 \\
\hline Same or next day appointment & 59.5 & 57.1 & 62.8 & 0.546 \\
\hline I am able to see the GP in the evening, at night/weekend & 72.8 & 71.9 & 70.3 & 0.509 \\
\hline \multicolumn{5}{|l|}{ Continuity and Coordination } \\
\hline The GP had my medical history available in front of him/her & 51.2 & 59.0 & 39.5 & $<0.0001$ \\
\hline $\begin{array}{l}\text { The GP knows important information about my } \\
\text { medical history }\end{array}$ & 80.4 & 87.2 & 69.8 & $<0.0001$ \\
\hline The GP knows my living conditions & 65.4 & 71.7 & 55.6 & $<0.0001$ \\
\hline $\begin{array}{l}\text { During the past two years, the GP asked me about all } \\
\text { the medications that I was taking }\end{array}$ & 76.6 & 86.7 & 60.9 & $<0.0001$ \\
\hline $\begin{array}{l}\text { It is difficult to get a referral to a medical specialist } \\
\text { from my GP }\end{array}$ & 10.1 & 8.9 & 10.7 & 0.257 \\
\hline \multicolumn{5}{|l|}{ Communication and Patient-Centred Care } \\
\hline The GP was polite & 94.8 & 95.6 & 94.2 & 0.157 \\
\hline The GP listened carefully to me & 92.5 & 93.1 & 91.6 & 0.233 \\
\hline The GP looked at me when I was talking & 88.4 & 88.2 & 91.0 & 0.053 \\
\hline The GP asked me questions about my health problem & 91.9 & 91.9 & 91.9 & 0.992 \\
\hline $\begin{array}{l}\text { I could not really understand what the GP was trying } \\
\text { to explain to me }\end{array}$ & 88.4 & 86.1 & 91.9 & $<0.0001$ \\
\hline \multicolumn{5}{|l|}{ Comprehensiveness } \\
\hline $\begin{array}{l}\text { The doctor asked me about other problems beyond that } \\
\text { for which I came }\end{array}$ & 74.3 & 76.5 & 71.4 & 0.011 \\
\hline $\begin{array}{l}\text { The GP is not only addressing my medical problems, but is } \\
\text { also able to help with my personal problems and concerns }\end{array}$ & 80.7 & 85.1 & 73.8 & $<0.0001$ \\
\hline $\begin{array}{l}\text { During the past } 12 \text { months, a GP talked to me about how } \\
\text { to stay healthy (diet, smoking, alcohol) }\end{array}$ & 72.6 & 81.2 & 60.1 & $<0.0001$ \\
\hline \multicolumn{5}{|l|}{ Patient Activation } \\
\hline The GP included me in the decisions about my treatment & 73.5 & 74.1 & 72.5 & 0.440 \\
\hline $\begin{array}{l}\text { After today's visit, I feel that I am able to deal better with } \\
\text { my health problem than before }\end{array}$ & 86.3 & 86.3 & 86.2 & 0.975 \\
\hline
\end{tabular}

${ }^{\mathrm{a}}$ Based on 1950 cases or the variable presence of chronic disease (yes/no)

feeling time pressure from the physician as being highly valued. Both of these items were ranked by more than $80 \%$ of respondents as being met. While not ranked as the most valued aspects of care by patients, long waittimes are being reported on the day of their visit to clinic, by most patients. In Greece most GPs do not typically book appointments, which may explain the long office wait times reported by patients in the present evaluation [4]. Wait times and proximity of primary care centres are quality indicators $[16,21]$. The challenges documented in present study in terms of wait times and access to primary care in non-urban areas have been previously identified in formal assessment of the primary care system in Greece and are important areas for quality improvement [4]. Importantly, while not assessed directly in the present study, patient out of pocket payments have been shown to limit access to primary health care services, a pattern which would be further increased by the economic crisis in Greece [4, 15]. 
Table 5 Patient value survey responses by quality domain - Proportion of participants who ranked as very important

\begin{tabular}{|c|c|c|c|c|}
\hline Variable & $\begin{array}{l}\% \text { Total } \\
n=219\end{array}$ & $\begin{array}{l}\% \text { Without } \\
\text { chronic disease } \\
n=102\end{array}$ & $\begin{array}{l}\text { \% Patients with } \\
\text { chronic disease } \\
n=117\end{array}$ & $p$-value \\
\hline \multicolumn{5}{|l|}{ Accessibility } \\
\hline The practice has extensive opening hours & 43.6 & 41.9 & 45.5 & 0.071 \\
\hline I can get an appointment easily at this practice & 47.7 & 45.3 & 50.5 & 0.666 \\
\hline I know how to get evening, night and weekend services & 47.2 & 50.4 & 43.6 & 0.416 \\
\hline The practice is close to where I live or work & 57.8 & 63.2 & 51.5 & 0.053 \\
\hline $\begin{array}{l}\text { I have a short waiting time on the phone when I } \\
\text { call this practice }\end{array}$ & 38.1 & 38.5 & 37.6 & 0.322 \\
\hline $\begin{array}{l}\text { The doctor does not give me the feeling to be under } \\
\text { time pressure }\end{array}$ & 59.4 & 58 & 61.2 & 0.632 \\
\hline $\begin{array}{l}\text { The doctor offers me his/her telephone or email to } \\
\text { contact for further questions }\end{array}$ & 29.4 & 28.7 & 29.3 & 0.923 \\
\hline I will keep my appointment & 34.7 & 30.9 & 38.3 & 0.268 \\
\hline \multicolumn{5}{|l|}{ Continuity and Coordination } \\
\hline The doctor has my medical records at hand & 42.1 & 41.1 & 46.9 & 0.144 \\
\hline $\begin{array}{l}\text { The doctor knows important information about my } \\
\text { medical background and health issues }\end{array}$ & 57.9 & 59.0 & 62.4 & 0.714 \\
\hline The doctor knows about my living situation & 28.4 & 27.7 & 29.2 & 0.811 \\
\hline $\begin{array}{l}\text { The doctor has prepared for the consultation by } \\
\text { reading my medical notes }\end{array}$ & 29.4 & 29.7 & 29.3 & 0.950 \\
\hline $\begin{array}{l}\text { The doctor gives me instructions on what to do when } \\
\text { things go wrong }\end{array}$ & 64.7 & 59.4 & 69.0 & 0.142 \\
\hline $\begin{array}{l}\text { I don't need to tell a receptionist or nurse details about } \\
\text { my health problem }\end{array}$ & 21.6 & 22.2 & 21.4 & 0.920 \\
\hline I inform the doctor how the treatment works out & 43.0 & 40.0 & 45.1 & 0.450 \\
\hline I can see another doctor if I think it is necessary & 29.8 & 29.3 & 30.5 & 0.854 \\
\hline \multicolumn{5}{|l|}{ Communication and Patient-Centered Care } \\
\hline The doctor is polite & 63.9 & 59.4 & 67.5 & 0.215 \\
\hline $\begin{array}{l}\text { The doctor makes me feel welcome by making } \\
\text { eye contact }\end{array}$ & 49.8 & 47.5 & 52.1 & 0.497 \\
\hline The doctor listens attentively & 68.8 & 69.3 & 68.1 & 0.849 \\
\hline $\begin{array}{l}\text { The doctor is aware of my personal, social and } \\
\text { cultural background }\end{array}$ & 13.7 & 13.9 & 13.7 & 0.968 \\
\hline $\begin{array}{l}\text { The doctor is not prejudiced because of my age, } \\
\text { gender, religion or culture }\end{array}$ & 35.2 & 34.7 & 35.9 & 0.848 \\
\hline $\begin{array}{l}\text { The doctor treats me as a person and not as a } \\
\text { medical problem }\end{array}$ & 57.8 & 52.5 & 62.1 & 0.154 \\
\hline $\begin{array}{l}\text { The doctor is respectful during physical examinations } \\
\text { and does not interrupt me }\end{array}$ & 46.8 & 41.6 & 50.9 & 0.172 \\
\hline The doctor takes me seriously & 54.7 & 48.5 & 59.6 & 0.103 \\
\hline The doctor understand me & 56.7 & 51.0 & 62.1 & 0.101 \\
\hline $\begin{array}{l}\text { The doctor asks me if I have any questions about } \\
\text { my health problems }\end{array}$ & 46.1 & 38.6 & 52.2 & 0.046 \\
\hline The doctor asks how I prefer to be treated & 22.5 & 20.7 & 24.5 & 0.544 \\
\hline $\begin{array}{l}\text { The doctor avoids disturbances of the consultation } \\
\text { by telephone calls etc. }\end{array}$ & 22.5 & 26.7 & 19.0 & 0.172 \\
\hline The people at the reception desk are polite and helpful & 36.1 & 35.7 & 35.8 & 0.992 \\
\hline I understand clearly what the doctor explains & 67.1 & 66.0 & 67.8 & 0.776 \\
\hline
\end{tabular}


Table 5 Patient value survey responses by quality domain - Proportion of participants who ranked as very important (Continued)

\begin{tabular}{|c|c|c|c|c|}
\hline \multicolumn{5}{|l|}{ Comprehensiveness } \\
\hline $\begin{array}{l}\text { The doctor asks about possible other problems besides the } \\
\text { one I came in for }\end{array}$ & 37.2 & 34.0 & 40.0 & 0.364 \\
\hline $\begin{array}{l}\text { The doctor gives me additional information about my } \\
\text { health problem }\end{array}$ & 20.1 & 18.8 & 21.4 & 0.639 \\
\hline $\begin{array}{l}\text { The doctor informs me about reliable sources of information } \\
\text { e.g. websites }\end{array}$ & 7.8 & 7.9 & 7.8 & 0.965 \\
\hline $\begin{array}{l}\text { Psychosocial issues (for example personal worries) can be } \\
\text { discussed if needed }\end{array}$ & 32.3 & 29.3 & 29.9 & 0.921 \\
\hline $\begin{array}{l}\text { The doctor gives all test results even if they show } \\
\text { abnormalities }\end{array}$ & 49.1 & 50.5 & 47.4 & 0.651 \\
\hline \multicolumn{5}{|l|}{ Patient Activation } \\
\hline $\begin{array}{l}\text { The doctor involves me in making decisions about } \\
\text { treatment }\end{array}$ & 37.7 & 34.0 & 41.2 & 0.277 \\
\hline I feel able to cope better with my health problem after the visit & 57.1 & 50.0 & 62.9 & 0.056 \\
\hline I have prepared for the consultation by keeping a symptom diary or preparing questions & 15.3 & 15.0 & 15.8 & 0.873 \\
\hline I tell the doctor what I want to discuss in this consultation & 26.1 & 28.0 & 23.9 & 0.495 \\
\hline I am prepared to ask questions and take notes & 15.3 & 19.0 & 11.4 & 0.120 \\
\hline $\begin{array}{l}\text { I am honest and not feel embarrassed to talk about my } \\
\text { health problem }\end{array}$ & 48.6 & 49.0 & 48.7 & 0.967 \\
\hline $\begin{array}{l}\text { I am open about my use of other treatments, such as } \\
\text { self-medication or alternative }\end{array}$ & 25.1 & 25.3 & 24.3 & 0.878 \\
\hline I adhere to the agreed treatment plan & 37.2 & 38.0 & 36.8 & 0.850 \\
\hline I can bring a family member/friend to the consultation & 18.5 & 17.8 & 19.3 & 0.781 \\
\hline I inform the doctor how the treatment works out & 42.7 & 45.1 & 40.0 & 0.781 \\
\hline
\end{tabular}

$p$-values report on significance comparison by presence of chronic disease

Primary care providers scored well in many aspects related to the communication and patient-centered care domain. In terms of areas for improvement, providers had moderate scores in the assessment of the patient's living conditions, and discussing problems beyond the reason for the current visit. These two factors were scored significantly lower by patients who did not have a chronic disease as compared to individuals with chronic conditions. Additionally significantly fewer respondents with a chronic disease indicated that the GP assisted in addition to addressing the

Table 6 Aspects rated very important by the majority of patients and the corresponding patient experience assessment scores

\begin{tabular}{lll}
\hline Top 11 values & $\begin{array}{c}\text { \% Who ranked as } \\
\text { "very important" }\end{array}$ & $\begin{array}{c}\text { \% Positive patient } \\
\text { experience rating }\end{array}$ \\
\hline The doctor listens attentively & 68.8 \\
I understand clearly what the doctor explains & 67.1 & 92.5 \\
The doctor gives me instructions on what to do when & 64.7 \\
things go wrong & 68.4 \\
The doctor is polite & 63.9 \\
The doctor does not give me the feeling to be under & 59.4 \\
time pressure & \\
The doctor knows important information about my medical & 57.9 \\
history and health issues & \\
The practice is close to where I live or work & 57.8 \\
The doctor treats me as a person and not as a medical problem & 57.8 \\
I feel able to cope better with my health problem after the visit & 57.1 \\
The doctor understand me & 56.7 \\
That the doctor takes me seriously & 54.7 \\
\hline
\end{tabular}


Table 7 Factors related to primary health care delivery that were ranked as most valued by patients surveyed

More than half of participants also indicated the following as very important:

- The doctor listens attentively

- I understand clearly what the doctor explains

- The doctor gives me instructions on what to do when things go wrong

- The doctor is polite

- The doctor does not give me the feeling to be under time pressure

- The doctor knows important information about my medical history and health issues

- The practice is close to where I live or work

- The doctor treats me as a person and not as a medical problem

- I feel able to cope better with my health problem after the visit

- The doctor understand me

- That the doctor takes me seriously

- That the doctor know when to refer me to a medical specialist

- That the doctor makes me feel welcome by making eye contact

- That the doctor is respectful during physical examinations and does not interrupt me

- That the doctor asks me if I have any questions

- That the doctor gives all test results even if they show abnormalities

- That I know which doctor will I see

- That I am honest and not feel embarrassed to talk about my health problem

- That I know which doctor will I see

- That the doctor asks me if I have any questions

patients' health problems with personal problems and concerns. The focus on urgent care issues and lack of comprehensive approach to family or community-based health care delivery is highlighted by this data - an issue that has been identified by other groups $[4,16,21]$.

Patient-involvement in decision making about their treatment plan was scored moderately. Interestingly this variable did not differ between patients with and without a chronic disease. Approximately 15\% of patients left the GPs office not feeling better prepared to deal with their medical condition, the reasons for this should be examined as an area for future research.

Several areas of improvement were identified in terms of the continuity of care received by patients. Importantly, only half of patient's surveyed reported the GP had their medical history available in front of them. Availability of medical history records was $60 \%$ among patients with chronic disease and $40 \%$ among individuals who did not have a chronic disease. It is possible that this finding is related to the lack of an effective appointment booking system as was the lack of a comprehensive electronic medical records system [4]. Although certain efforts have been made in the recent years, primary care physicians currently only have electronic access to a record of patient's prescriptions. Respondents with a chronic disease were significantly more likely to report receiving advice related to staying healthy (diet, smoking, alcohol), compared to individuals without a chronic disease (81\% vs. $60 \% ; p<0.0001)$. All variables related to continuity and coordination were scored significantly lower among patients without a chronic condition, when compared to individuals with chronic disease.

Data from the present study is consistent with previous reports regarding the weaknesses of PHC system in Greece including the lack of integration across the health care system, limited use of multidisciplinary teams, poor coordination and continuity of care, as well as, a lack of focus on disease prevention and health promotion [4, 16, 22-25]. Using the quality standards set out by the QUALICOPC study group, Greece has scored low across all domains assessed with the exception of the continuity domain where a moderate ranking was received [17].

\section{Implications to practice and policy}

Data gathered will assist with documenting the patient perspective and may be used to improve the quality of PHC services in Greece through an increased focus on patient-centered approaches especially in a period where a primary care reform is presently being examined by the current government and Greece struggles to develop a high quality system to respond to the population health needs. Study findings may also have application to other national health care systems and policy in countries with similar context and infrastructure.

Countries that have focused on strengthening PHC have emphasized the importance of patient-centered practices [17]. Internationally, quality improvement efforts in the primary care setting have emphasized issues such as patients with multiple co-morbidities, integrated primary care delivery, and workforce and technology (e.g. e-Health) [16, 26-28]. Studies have shown positive correlations between the patient-centered approach and patient experiences such as patient satisfaction [12, 29], patient recall of the content of the health care services [30], patient adherence [30], patient health outcomes [8, $12,31,32]$, health care utilization $[8,30]$ and provider satisfaction [30]. The financial crisis in Greece necessitates a closer look at proven models, such as the patientcentered model of care, for improving population health, reducing inequalities, and spending. This is a fertile area for GPs and the primary care health care system to invest energy and international experience and collaborations can serve to guide these efforts [33].

Training programs, which engage GP's in more patient-centered communication have been shown by to 
lead to an increased likelihood that the interaction would be more closely aligned with the patient's psychosocial needs and improve patient's compliance and outcomes [30]. Given this evidence, we would recommend government as well as medical schools within Greece look at strengthening the emphasis on patient-centered care within medical school curricula and continuing medical education programs. A recommendation that was brought forward in a recent report examining primary health care in Europe [16, 21, 34].

Our study identified a significant gap in primary care provider's access to patient medical history, a factor, which was highly valued by patients surveyed. These results suggest that policy-makers should continue efforts to improve $\mathrm{PHC}$ services by adopting the Electronic health Record (EHR), which is expected to improve all six dimensions of quality care identified by the Institute of Medicine (safety, timeliness, effectiveness, efficiency, equity, and patient-centeredness) [35]. Unfortunately, at present, only the prescription part of the EHR is operational and there is feedback from providers that this tool is time consuming. International experience based on episode of care and ICPC-2 classification could be used to inform quality improvement activities related to the introduction of EHRs in Greece [36, 37].

Our study also documented several gaps in care for individuals who did not have a diagnosed chronic condition, in particular in terms of comprehensiveness of care. There were several important differences documented between respondents without a chronic disease and those with a chronic condition in terms of their experience with the primary care system. This data may highlight a lack of attention to preventative care within the national health care system in Greece and is consistent with previous reports $[4,16,38]$. The financial constraints has meant several areas of international importance in the field of primary care are not on the agendas of GPs in Greece including frailty, chronic disease prevention, selfmanagement, and multi-morbidity [33]. Given the high rates of chronic disease documented in Greece, the delay in diagnosis of chronic diseases such as COPD and lung cancer, and increased focus on preventative medicine and chronic disease-management within the primary care system is recommended [39]. Highly costeffective interventions are available and have been tested in other countries, as well as in Greece, which should be implemented as part of the national primary care system [40]. Likewise, the role of primary care and public health nurses must be urgently discussed and there is evidence that the capacity of nurses serving in the Greek primary care is underutilized [41-43]. Finally, the development of quality standards in PHC services which are informed by patient-centered models of care are particularly important during the present austerity period in Greece.

\section{Limitations}

The present study has some methodological limitations that should be understood when interpreting findings. First the recruitment of GP's was not via random selection but rather used a local champion who assisted with GP recruitment in each of the seven health regions in Greece and as such may not necessarily be representative of all GPs in Greece. Our sample primarily represented the views of GPs who serve in the public sector. The number of private practice GPs included in the study was small $(n=17)$, and as such was not sufficiently representative of all private practices in Greece, thus we are not certain to what extent the views of GPs serving in the private sector differ. Given the study required patients to read and/or write in Greek our findings do not represent this patient population. The study results may be subject to observer bias, which may have resulted in providers increasing their performance during the period in which survey data was collected. Additionally, the nature of the present survey required that patients be able to read in Greek and as such is not representative of patient's who are unable to read and may in particular not be representative of lower income individuals, individuals with disabilities, and those whose mother tongue is something other than Greek. Furthermore, although the sample size of the study is relatively large, there is no data available regarding the non-responding patients thus inducing a potential source of selection bias. The present study used a previously validated tool to assess patient-valued and experiences but may not assess all aspects of care that are valued by patients. Finally, as has been reported by the QUALICOPC authors previously patient values may be a reflection of their experience to date in the primary health care system. For example in low performing health care system patients may have lower expectations about health care delivery and rank importance differently. As such information from patient value assessments should be considered one but not the only source of information for informing quality improvement activities [17].

\section{Conclusions}

In summary, our study presents data about patient's experiences and values across the 5 domains of primary health care delivery: Accessibility, Continuity \& Coordination, Communication \& Patient-Centred Care, Patient Activation, Comprehensiveness. A positive finding of the survey is that most of the patients (especially patients with chronic disease, who visit primary care unit more regularly) surveyed report that their health needs are being met. Several areas for quality improvement related in particular to access, comprehensiveness, and prevention have been identified which can be used to inform quality improvement activities to strengthen primary care delivery in Greece during a period where national health care reform is under discussion. 


\section{Abbreviations}

GP: General practitioner; ELEGEIA: Greek Association of General Practitioners; PHC: Primary Health Care; NIVEL: Netherlands Institute for Health Services Research

\section{Acknowledgements}

The QUALICOPC project is carried out by an international network of partner institutes and coordinated by Netherlands Institute for Health Services Research (NIVEL). This study was furthermore conducted in collaboration with the University of Crete and the Greek Association of General Practitioners (ELEGEIA). The Greek QUALICOPC team: Ioannis Dakoronias, MD. Health Centre of Markopoulo, Sah Hamid Alexandros, MD. Health Centre of Thera, Aristofanes Paganas, MD. Health Centre of Litochoro, Dimitrios Ellinas, MD. Health Centre of Prinou, Vesela Polyzou, MD. Health Centre of Trikala, Ioannis Lentzas, MD. Health Centre of Simmopoulo.

\section{Funding}

The QUALICOPC study was funded by the European Commission (FP7/2007-2013)

\section{Availability of data and materials}

Data and materials for this study are available from the authors upon reasonable request. Due to restrictions stated in our ethical approvals data are not available on public data repositories.

\section{Authors' contributions}

WB and WS are the leads for the QUALICOPC study and designed the overall study for this multi-national study. GD was the local project coordinator and in charge of data collection and P-BM assisted in recruitment and data collection activities. SP and AB performed statistical analysis and produced all tables. CL, SP, $C T, A B$ and $G D$ interpreted the data and prepared the manuscript. All authors commented on the draft and approved the final manuscript.

\section{Competing interests}

The authors declare they have no competing interests.

\section{Consent for publication}

Not applicable.

\section{Ethics approval and consent to participate}

Ethical approval was received from Bioethical Committee of the University General Hospital of Heraklion (number protocol: 7655/7-7-2011). Written informed consent was obtained from all patients and participant responses remained anonymous.

\section{Publisher's Note}

Springer Nature remains neutral with regard to jurisdictional claims in published maps and institutional affiliations.

\section{Author details}

${ }^{1}$ Faculty of Medicine, University of Crete, Heraklion, Crete, Greece. ${ }^{2}$ Division of Prevention and Rehabilitation, University of Ottawa Heart Institute, Ottawa, ON, Canada. ${ }^{3}$ The Greek Association of General Practitioners (ELEGEIA), Thessaloniki, Greece. ${ }^{4}$ Netherlands Institute for Health Services Research (NIVEL), Utrecht, Netherlands.

\section{Received: 8 October 2015 Accepted: 24 March 2017} Published online: 05 April 2017

\section{References}

1. Schafer WL, Boerma WG, Kringos DS, De Maeseneer J, Gress S, Heinemann S, Rotar-Pavlic D, Seghieri C, Svab I, Van den Berg MJ, Vainieri M, Westert GP, Willems S, Groenewegen PP. QUALICOPC, a multi-country study evaluating quality, costs and equity in primary care. BMC Fam Pract. 2011; 12:115-2296-12-115.

2. Pullicino G, Sciortino P, Calleja N, Schafer W, Boerma W, Groenewegen P. Comparison of patients' experiences in public and private primary care clinics in Malta. Eur J Public Health. 2015:25(3):399-401.

3. Delnoij D, Van Merode G, Paulus A, Groenewegen P. Does general practitioner gatekeeping curb health care expenditure? J Health Serv Res Policy. 2000;5(1):22-6.
4. Groenewegen PP, Jurgutis A. A future for primary care for the Greek population. Qual Prim Care. 2013;21(6):369-78.

5. Bleich SN, Ozaltin E, Murray CK. How does satisfaction with the health-care system relate to patient experience? Bull World Health Organ. 2009;87(4):271-8.

6. Davis K, Schoenbaum SC, Audet AM. A 2020 vision of patient-centered primary care. J Gen Intern Med. 2005;20(10):953-7.

7. Starfield B, Shi L, Macinko J. Contribution of primary care to health systems and health. Milbank Q. 2005;83(3):457-502.

8. Friedberg MW, Hussey PS, Schneider EC. Primary care: a critical review of the evidence on quality and costs of health care. Health Aff (Millwood). 2010;29(5):766-72.

9. Stewart M. Continuity, care, and commitment: the course of patientclinician relationships. Ann Fam Med. 2004;2(5):388-90.

10. Helitzer DL, Lanoue M, Wilson B, de Hernandez BU, Warner T, Roter D. A randomized controlled trial of communication training with primary care providers to improve patient-centeredness and health risk communication. Patient Educ Couns. 2011:82(1):21-9.

11. Bodenheimer T, Lorig K, Holman H, Grumbach K. Patient self-management of chronic disease in primary care. JAMA. 2002;288(19):2469-75.

12. Taylor K. Paternalism, participation and partnership - the evolution of patient centeredness in the consultation. Patient Educ Couns. 2009:74(2):150-5.

13. Smith RC, Lyles JS, Mettler JA, Marshall AA, Van Egeren LF, Stoffelmayr BE, Osborn GG, Shebroe V. A strategy for improving patient satisfaction by the intensive training of residents in psychosocial medicine: a controlled, randomized study. Acad Med. 1995;70(8):729-32.

14. Ong LM, de Haes JC, Hoos AM, Lammes FB. Doctor-patient communication: a review of the literature. Soc Sci Med. 1995;40(7):903-18.

15. Souliotis K, Golna C, Tountas Y, Siskou O, Kaitelidou D, Liaropoulos L. Informal payments in the Greek health sector amid the financial crisis: old habits die last...Eur J Health Econ. 2016;17(2):159-70. doi:10.1007/s10198-015-0666-0.

16. Kringos DS, Boerma W, van der Zee J, Groenewegen P. Europe's strong primary care systems are linked to better population health but also to higher health spending. Health Aff (Millwood). 2013;32(4):686-94.

17. Schafer WL, Boerma WG, Murante AM, Sixma HJ, Schellevis FG, Groenewegen PP. Assessing the potential for improvement of primary care in 34 countries: a cross-sectional survey. Bull World Health Organ. 2015:93(3):161-8.

18. Schafer WL, Boerma WG, Kringos DS, De Ryck E, Gress S, Heinemann S, Murante AM, Rotar-Pavlic D, Schellevis FG, Seghieri C, Van den Berg MJ, Westert GP, Willems S, Groenewegen PP. Measures of quality, costs and equity in primary health care instruments developed to analyse and compare primary care in 35 countries. Qual Prim Care. 2013;21(2):67-79.

19. Karakolias S.E. PNM. The newly established Unified Healthcare Fund (EOPYY): Current situation and proposed structural changes, towards an upgraded,odel of primary health care, in Greece. Health. 2014;6:809-821.

20. Polyzos N, Karakolias S, Dikeos C, Theodorou M, Kastanioti C, Mama K, Polizoidis P, Skamnakis C, Tsairidis C, Thireos E. The introduction of Greek Central Health Fund: Has the reform met its goal in the sector of Primary Health Care or is there a new model needed? BMC Health Serv Res. 2014; 14:583-014-0583-4.

21. Kringos D, Boerma W, Hutchinson A, Saltman R. Building Primary Care in a Changing Europe. 2015.

22. Lionis C, Petelos E. The impact of the financial crisis on the quality of care in primary care: an issue that requires prompt attention. Qual Prim Care. 2013: 21(5):269-73.

23. Brotons $C$. Control of cardiovascular risk factors in primary healthcare: do we control the factors or the risk? Med Clin (Barc). 2005;124(11):415-6.

24. Tsiligianni I, Anastasiou F, Antonopoulou M, Chliveros K, Dimitrakopoulos S, Duijker G, Kounalakis D, Makri K, Petraki C, Prokopiadou D, Stefanaki I, Symvoulakis E, Tsakountakis N, Vasilopoulos T, Vittorakis C, Lionis C, Cretan Practice based Primary Care Research Network 'G. Lambrakis', Clinic of Socia and Family Medicine, School of Medicine, University of Crete. Greek rural GPs' opinions on how financial crisis influences health, quality of care and health equity. Rural Remote Health. 2013;13(2):2528.

25. Lionis C. Is there any room for General Practice in Greece? A proposal to scientific and academic stakeholders. Hippokratia. 2014;18(4):383.

26. Jackson GL, Powers BJ, Chatterjee R, Bettger JP, Kemper AR, Hasselblad V, Dolor RJ, Irvine RJ, Heidenfelder BL, Kendrick AS, Gray R, Williams JW. Improving patient care. The patient centered medical home. A Systematic Review. Ann Intern Med. 2013;158(3):169-78.

27. Brown L, Oliver-Baxte J, Bywood P. International trends and initiatives in primary health care... 2013;RESEARCH ROUNDup Issue 32. 
28. World Health Organization. Facts and figures: Trends in Primary Care.. Retrieved 4 July 2013.

29. Saha S, Beach MC, Cooper LA. Patient centeredness, cultural competence and healthcare quality. J Natl Med Assoc. 2008;100(11):1275-85.

30. Lionis C, Symvoulakis EK, Vardavas Cl. Implementing family practice research in countries with limited resources: a stepwise model experienced in Crete. Greece Fam Pract. 2010;27(1):48-54.

31. Frederikson LG. Exploring information-exchange in consultation: the patients' view of performance and outcomes. Patient Educ Couns. 1995; 25(3):237-46.

32. Little P, Everitt H, Williamson I, Warner G, Moore M, Gould C, Ferrier K, Payne S. Preferences of patients for patient centred approach to consultation in primary care: observational study. BMJ. 2001;322(7284):468-72.

33. Lionis C. Financial crisis and primary health care in Greece; is it time for family medicine? Fam Med \& Prim Care Rev. 2015;17(3):225-7.

34. Kringos D, Boerma W, Bourgueil Y, Cartier T, Dedeu T, Hasvold T, Hutchinson A, Lember M, Oleszczyk M, Rotar Pavlic D, Svab I, Tedeschi P, Wilm S, Wilson A, Windak A, Van der Zee J, Groenewegen P. The strength of primary care in Europe: an international comparative study. Br J Gen Pract. 2013;63(616):e742-50.

35. Fleming NS, Herrin J, Roberts W, Couch C, Ballard DJ. Patient-centeredness and timeliness in a primary care network: baseline analysis and power assessment for detection of the effects of an electronic health record. Proc (Bayl Univ Med Cent). 2006;19(4):314-9.

36. Kounalakis DK, Lionis C, Okkes I, Lamberts H. Developing an appropriate EPR system for the Greek primary care setting. J Med Syst. 2003;27(3):239-46.

37. Minas M, Koukosias N, Zintzaras E, Kostikas K, Gourgoulianis KI. Prevalence of chronic diseases and morbidity in primary health care in central Greece: an epidemiological study. BMC Health Serv Res. 2010;10:252-6963-10-252.

38. Brotons C, Bjorkelund C, Bulc M, Ciurana R, Godycki-Cwirko M, Jurgova E, Kloppe P, Lionis C, Mierzecki A, Pineiro R, Pullerits L, Sammut MR, Sheehan M, Tataradze R, Thireos EA, Vuchak J. EUROPREV network. Prevention and health promotion in clinical practice: the views of general practitioners in Europe. Prev Med. 2005;40(5):595-601.

39. Busse R, Blumel M, Scheller-Kreinsen D, Zentner A. Tackling chronic disease in Europe, observatory study, vol. 20. 2010.

40. Franco OH, der Kinderen AJ, De Laet C, Peeters A, Bonneux L. Primary prevention of cardiovascular disease: cost-effectiveness comparison. Int J Technol Assess Health Care. 2007;23(1):71-9.

41. Markaki A, Alegakis A, Antonakis N. Kalokerinou-Anagnostopoulou A, Lionis C. Exploring training needs of nursing staff in rural Cretan primary care settings. Appl Nurs Res. 2009;22(2):138-43. discussion 144-5.

42. Lionis C, Symvoulakis EK, Markaki A, Vardavas C, Papadakaki M, Daniilidou N, Souliotis K, Kyriopoulos I. Integrated primary health care in Greece, a missing issue in the current health policy agenda: a systematic review. Int J Integr Care. 2009;9:e88.

43. Markaki A, Antonakis N, Philalithis A, Lionis C. Primary health care nursing staff in Crete: an emerging profile. Int Nurs Rev. 2006;53(1):16-8.

\section{Submit your next manuscript to BioMed Central and we will help you at every step:}

- We accept pre-submission inquiries

- Our selector tool helps you to find the most relevant journal

- We provide round the clock customer support

- Convenient online submission

- Thorough peer review

- Inclusion in PubMed and all major indexing services

- Maximum visibility for your research

Submit your manuscript at www.biomedcentral.com/submit

) Biomed Central 